\title{
The role of the pharmaceutical industry in neurologic education
}

\author{
Douglas J. Gelb, MD, PhD
}

\section{Background}

E ach year, the American Academy of Neurology (AAN)'s A.B. Baker Section on Neurologic Education conducts an Education Colloquium at the AAN annual meeting. The goals of the Colloquium are to heighten awareness, stimulate creative approaches, and foster dialogue among members regarding current trends, challenges, and opportunities in neurologic education. The theme of the $2004 \mathrm{Ed}-$ ucation Colloquium was the role of the pharmaceutical industry in neurologic education.

Pharmaceutical companies are increasingly involved in neurologic education, partly because of recent dramatic advances in the pharmacotherapy of neurologic diseases, and partly because of economic trends affecting medicine and academic medical centers. The growing role of the pharmaceutical industry in education has both positive and negative consequences.

Neurologists need to be informed about currently available medications and the clinical trials that provide evidence for their effectiveness. A major source of information is the material prepared by the pharmaceutical companies and approved by the Food and Drug Administration for drug labeling. For their part, pharmaceutical compa- nies need to keep abreast of current trends and perceived needs in clinical and academic neurology. Furthermore, researchers in industry and researchers in academic neurology departments both benefit from openly communicating with each other. Thus, there are many ways in which industry involvement in neurologic education is desirable.

At the same time, this interaction is fraught with risks, because the priorities of the pharmaceutical industry differ from those of clinical and academic medicine. Pharmaceutical companies will predictably emphasize information that puts their products in the best possible light, introducing biases that can be difficult for trainees and even teachers to recognize (for example, focusing on distinctions that are not clinically meaningful, downplaying adverse results, and minimizing the role of non-pharmacologic management and the use of generic and off-patent drugs). Financial support and personal relationships can improperly influence how neurologists and trainees make decisions about medications, how teachers present information (and even how they decide what topics to cover), and how investigators conduct and interpret research.

I served as the director of the 2004 Education Colloquium. Sec- tion members participate in neurologic education at a variety of different levels, from medical student education through continuing medical education (CME), so I tried to include discussion of the pharmaceutical industry's role in neurologic education at all of those levels. I invited panelists with a diverse range of relevant professional experiences, but I asked each one to focus on only a subset of the overall topic. Thus, although each panelist presented background information including the literature relevant to his assigned topic, no panelist was asked to present a more general literature review. In this article, I summarize the panelists' remarks, but also provide an overview of the literature. Space constraints prevent a comprehensive review, but I have tried to present a representative sample of the types of investigations that have been conducted in this field. The results of many of these investigations can be interpreted in more than one way, and this topic tends to evoke strong emotional responses, so there is a risk of interpreting the results in a way that conforms to preconceived notions. I have tried to set aside my own biases and provide a balanced and critical analysis of the results. If there are flaws in the analysis, or in the review itself, they are en- 
tirely my responsibility and not the fault of the panelists.

\section{Literature Overview}

Studies clearly indicate that a physician's clinical practice can be influenced by personal interactions with pharmaceutical representatives. For example, physicians who meet with representatives from a pharmaceutical company are more likely to request formulary additions for that company's drug than for comparable drugs produced by other companies, and they are more likely to make such requests than physicians who do not meet with pharmaceutical representatives. ${ }^{1}$ The acceptance of meals or travel expenses for sponsored educational meetings is associated with more frequent prescription of the sponsor's medications and more formulary addition requests for those medications. ${ }^{2,3}$ The frequency with which physicians (including residents) prescribe new drugs correlates with the physicians' interactions with representatives of the companies that make the drugs. ${ }^{2-5}$

The fact that pharmaceutical industry interactions affect physicians' clinical practice does not necessarily imply that such interactions are inappropriate. It could be that as a result of these interactions, physicians become more aware of legitimate and compelling advantages of some drugs, and adjust their behavior accordingly. After all, one of the objectives of CME is to alert practicing physicians to new developments, and to alter behavior if it is outmoded. What is the evidence that physician-industry interactions result in inappropriate changes in clinical practice?

The evidence is suggestive, but not conclusive. Reviews of CME show that the sponsor's drug is preferentially presented. ${ }^{2}$ Similarly, articles in company-sponsored supplements are more promotional than articles elsewhere. ${ }^{3}$ This does not necessarily imply that speakers or authors are tailoring their comments to suit the sponsor, however. The sponsor may simply be identifying and soliciting presentations from individuals who have independently concluded that the sponsor's drug is worth highlighting. To demonstrate an unequivocally harmful effect of industry participation, it would be necessary to show that individual presenters alter the material they present depending on who is sponsoring the presentation.

Another concern about physicianindustry interactions relates to the fact that surveyed physicians have mistaken beliefs about medications, and these beliefs correlate with pharmaceutical company promotional material. ${ }^{6}$ This does not prove that the mistaken beliefs are the result of direct interactions with pharmaceutical representatives, however. The physicians may have been influenced by articles in the popular press or advertisements to the lay public, or by anecdotal experience that differs from the results of controlled trials.

Most residents and practicing physicians believe that gifts from pharmaceutical representatives do not influence their behavior, but they think that such gifts affect the prescribing practices of other physicians. ${ }^{7,8}$ The degree to which they believe they are immune to such influence correlates with the number of gifts they have received. ${ }^{2,9}$ Residents are far more likely to consider interactions with pharmaceutical representatives appropriate if they train at a program granting free access to representatives than if they train at a program with restrictions on such interactions. ${ }^{2,10}$ The frequency of contact with pharmaceutical representatives among practicing physicians also correlates with the frequency of such contact during training. ${ }^{10}$ The result is a "positive feedback loop" perpetuated from one generation of trainees to the next.

An obvious limitation to research regarding physician attitudes is the difficulty in determining whether the attitudes and perceptions are accurate. It is conceivable that increased exposure to pharmaceutical representatives builds immunity to inappropriate tactics and promotes more critical thinking among residents and practicing physicians. This seems unlikely, however, based on the work of social scientists who study gift behavior, bias, and conflict of interest. ${ }^{4,9}$ Gifts of any size impose on the recipient a sense of indebtedness and obligation to demonstrate gratitude, to use the gift, and to reciprocate. Whether or not the recipient is aware of it, this feeling of obligation influences behavior.

Indeed, even though physicians may believe themselves immune to bribery and flattery, non-physicians believe otherwise. Patients are more likely than physicians to believe that pharmaceutical gifts are inappropriate, and that they may influence physician behavior., ${ }^{9,11}$ Moreover, the pharmaceutical industry clearly views the interaction with physicians as an effective way of influencing prescribing behavior. ${ }^{3,4}$

\section{Colloquium Summary}

The first panelist to speak at the Education Colloquium, Dr. Sid Gilman, has served for two decades on the FDA Peripheral and Central Nervous System Drugs Advisory Committee, and he has served as a consultant for a number of pharmaceutical companies. While he agreed that some current practices raise concerns, he cautioned against overreaction and demonization of the pharmaceutical industry. He cited the dramatic developments in neurologic therapeutics over the past quarter century, and encouraged academic neurologists to collaborate closely with industry in developing and testing new therapies.

The second panelist, Dr. Seth Landefeld, is an internist and geriatrician who has conducted original research regarding the effects of physician-industry interactions, ${ }^{1}$ and he has helped the Society of General Internal Medicine develop and promote strong policies regarding interactions with the pharmaceutical industry. Dr. Landefeld reviewed much of the literature summarized earlier in this article, and offered concrete examples to illustrate the sense of obligation felt by the recipients of gifts. While he acknowledged the complexities of the issue and the many practical 
ramifications, Dr. Landefeld argued that firm organizational policies grounded in explicit ethical standards can and should be developed. He urged Section members to take an active role in developing such standards.

The next panelist, Dr. Robert Griggs, is Editor-in-Chief of Neurology. He had been asked to discuss the pharmaceutical industry's involvement in neurologic publications. Dr. Griggs explained that without the revenue derived from industry-sponsored advertisements, journals would have to cut services and raise subscription prices dramatically. He discussed the question of monitoring advertisements for accuracy, and he explained why Neurology does not take responsibility for advertisement content. $\mathrm{He}$ also addressed the issues of industry-sponsored research, industrysponsored supplements, and reviewer conflict of interest, ultimately advocating that authors and reviewers adhere to a strict policy of disclosure and that readers maintain a strong sense of caveat emptor ("let the buyer beware").

Dr. Timothy Pedley, the fourth panelist to speak, had been assigned the topic of pharmaceutical industry involvement in continuing neurologic education. Dr. Pedley has served as president of the American Epilepsy Society and as chair of the AAN's Science Committee, Scientific Program Subcommittee, and Meeting Management Committee. Just as Dr. Griggs had stressed the pharmaceutical industry's role in underwriting the substantial costs involved in producing a professional journal, Dr. Pedley highlighted the expense involved in mounting large national meetings. He pointed out that the absence of industry support would necessitate higher registration fees and fewer amenities. Despite these practical considerations, Dr. Pedley expressed concerns about industry support of CME. He noted the emergence of medical education and communication companies (MECCs), ostensibly independent agencies that function in many cases as surrogates for pharmaceutical companies. Dr. Pedley advocated strong guidelines establishing unambiguous boundaries between educational and promotional activities, and vigilant enforcement of those guidelines.

The same financial constraints that have led to increased reliance on pharmaceutical industry support for neurologic publications and continuing neurologic education also apply to the training of neurology residents and fellows. Drs. Gilman, Griggs, and Pedley have all served as chairs of academic neurology departments. All of them reported that departments have come to rely on extensive support from the pharmaceutical industry for essential educational activities. Departments that reject industry support incur a substantial burden.

The final panelist to speak was Dr. R. Michael Poole, who currently works in the pharmaceutical industry, but previously practiced neurology both in an academic department and in private practice. Dr. Poole reminded the group that the academic community and the pharmaceutical industry share many goals, and their relationship should not be adversarial. Similar views had been expressed already by some of the other panelists, notably Dr. Gilman and Dr. Griggs. Dr. Poole pointed out that because of regulatory requirements, pharmaceutical companies must provide the most carefully reviewed and detailed information available about their drugs. He challenged neurologists to ask probing questions of pharmaceutical representatives and to take advantage of the information that companies are required to provide.

Audience members expressed a wide range of opinions regarding many different aspects of the panelists' remarks. Several audience members voiced concerns regarding the pervasiveness of industry involvement in national meetings and professional journals. As one example, they noted that residents and fellows are often unaware of industry sponsorship of journal supplements. One of the audience members who spoke was Michael Williams, the chair of the AAN's Ethics, Law and Humanities Committee. He announced that the AAN created a Pharmaceutical Guideline Task Force a year ago. As Chair of the Task Force, Dr. Williams invited interested audience members to contact him with comments and suggestions.

The Education Colloquium was intended to be an educational forum. Not surprisingly, the Colloquium failed to resolve any issues or establish a clear consensus. Nonetheless, it helped to heighten awareness of issues that will grow in importance. At both an individual level and an organizational level, neurologists will eventually have to make some explicit and difficult decisions regarding the proper role of the pharmaceutical industry in neurologic education.

\section{Acknowledgment}

The author thanks the Education Colloquium speakers, Drs. Sid Gilman, Robert Griggs, Seth Landefeld, Timothy Pedley, and R. Michael Poole, for their enthusiastic participation and outstanding presentations. $\mathrm{He}$ is also grateful to the General Counsel of the AAN, Murray Sagsveen, for providing extensive background material.

\section{References}

1. Chren M-M, Landefeld S. Physicians' behavior and their interactions with drug companies: a controlled study of physicians who requested additions to a hospital drug formulary. JAMA 1994;271:684-689.

2. Wazana A. Physicians and the pharmaceutical industry. Is a gift ever just a gift? JAMA 2000;283:373-380.

3. Moynihan R. Who pays for the pizza? Redefining the relationships between doctors and drug companies. 1: Entanglement. BMJ 2003;326:1189-1192.

4. Dana J, Loewenstein G. A social science perspective on gifts to physicians from industry. JAMA 2003;290:252-255.

5. Watkins C, Moore L, Harvey I, Carthy P, Robinson E, Brawn R. Characteristics of general practitioners who frequently see drug industry representatives: national cross sectional study. BMJ 2003;326:11781179

6. Avorn J, Chen M, Hartley R. Scientific versus commercial sources of influence on the prescribing behavior of physicians. Am J Med 1982;73:4-8.

7. Steinman MA, Shlipak MG, McPhee SJ. Of principles and pens: attitudes and practices 
of medicine housestaff toward pharmaceutical industry promotions. Am J Med 2001; 110:551-557.

8. Schumock GT, Walton SM, Park HY, et al. Factors that influence prescribing decisions. Ann Pharmacother 2004;38:557562.
9. Katz D, Caplan AL, Merz JF. All gifts large and small: toward an understanding of the ethics of pharmaceutical industry giftgiving. Am J Bioethics 2003;3:39-46.

10. McCormick BB, Tomlinson G, Brill-Edwards P, Detsky AS. Effect of restricting contact between pharmaceutical company represen- tatives and internal medicine residents on posttraining attitudes and behavior. JAMA 2001;286:1994-1999.

11. Gibbons RV, Landry FJ, Blouch DL, et al. A comparison of physicians' and patients' attitudes toward pharmaceutical industry gifts. J Gen Intern Med 1998;13:151-154. 


\title{
Neurology
}

\author{
The role of the pharmaceutical industry in neurologic education \\ Douglas J. Gelb \\ Neurology 2005;64;E7-E10 \\ DOI 10.1212/01.WNL.0000152729.72672.B7
}

This information is current as of January 24, 2005

Updated Information \&

Services

References

Citations

Permissions \& Licensing

Reprints including high resolution figures, can be found at:

http://n.neurology.org/content/64/2/E7.full

This article cites 10 articles, 2 of which you can access for free at: http://n.neurology.org/content/64/2/E7.full\#ref-list-1

This article has been cited by 2 HighWire-hosted articles: http://n.neurology.org/content/64/2/E7.full\#\#otherarticles

Information about reproducing this article in parts (figures,tables) or in its entirety can be found online at:

http://www.neurology.org/about/about_the_journal\#permissions

Information about ordering reprints can be found online:

http://n.neurology.org/subscribers/advertise

Neurology ${ }^{\circledR}$ is the official journal of the American Academy of Neurology. Published continuously since 1951, it is now a weekly with 48 issues per year. Copyright. All rights reserved. Print ISSN: 0028-3878. Online ISSN: 1526-632X.

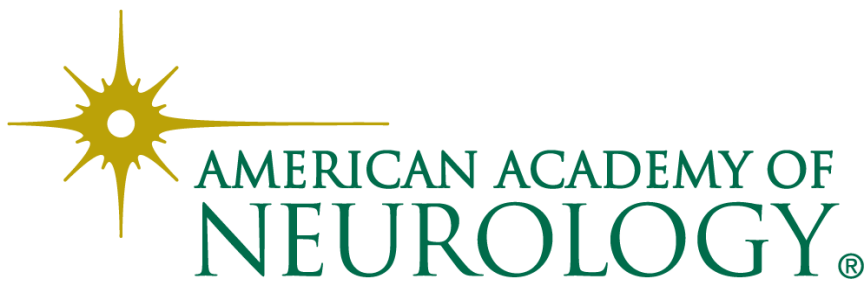

